\title{
Predicting ventilator-associated pneumonia
}

\author{
Tom McEnery ${ }^{1,2}$, Ignacio Martin-Loeches ${ }^{1,2,3}$
}

${ }^{1}$ Department of Intensive Care Medicine, Multidisciplinary Intensive Care Research Organization (MICRO), ${ }^{2}$ Department of Clinical Medicine, Trinity College, Wellcome Trust-HRB Clinical Research Facility, St James Hospital, Dublin, Ireland; ${ }^{3}$ Hospital de Barcelona, IDIBAPS, CIBERes, Barcelona, Spain

Correspondence to: Ignacio Martin-Loeches. Department of Anaesthesia and Critical Care Medicine, St James's Hospital, Dublin, Ireland. Email: drmartinloeches@gmail.com.

Provenance and Peer Review: This article was commissioned by the editorial office, Annals of Translational Medicine. The article did not undergo external peer review.

Comment on: Liu W, Jiao Y, Xing H, et al. Active surveillance of ventilator-associated pneumonia in the intensive care unit and establishment of the risk grading system and effect evaluation. Ann Transl Med 2019;7:617.

Submitted Feb 06, 2020. Accepted for publication Mar 04, 2020.

doi: $10.21037 /$ atm.2020.03.173

View this article at: http://dx.doi.org/10.21037/atm.2020.03.173

Ventilator-associated pneumonia (VAP) remains one of the most important causes of morbidity and mortality in the intensive care unit (ICU), despite decades of research on its identification, prevention and treatment. VAP also represents a significant economic burden on healthcare systems, typically adding 7 days to the average ICU length of stay (1) and increasing the cost of an ICU stay four-fold (2). Prevalence estimates vary widely, likely as a consequence of differing background populations, surveillance methods and the lack of a gold standard test for VAP. Most epidemiological studies report an incidence of 2-16 per 1,000 ventilator days (3). Incidence does appear to be declining in many regions, likely due to greater recognition and a focus on preventative strategies in the ICU, not least with early extubation, refined antimicrobial usage and ventilator care 'bundles', such as the successful Zero-VAP project in Spain (4). Active surveillance for VAP appears to result in reduced incidence (5) though this is controversial, and may just reflect stricter definitions for VAP $(6,7)$. This latter observation led the Centre for Disease Control (CDC, USA) to shift to surveillance of so-called ventilator-associated complications (VAC) in 2013 (8), though the latest European guideline have not followed their lead, citing a lack of sensitivity and specificity (9).

Nevertheless, the early identification of those at most risk of developing VAP is a worthwhile aim, particularly in resource-limited settings where costs associated with guideline-mandated care and VAP bundles can be significant.
The paper by Liu and colleagues (10) published in the November edition of Annals of Translational Medicine is thus a laudable effort to develop a risk-grading system for patients mechanically ventilated in the ICU. A total of 1,513 patients admitted to 6 ICUs in Mongolia underwent active surveillance for VAP, with diagnostic criteria based on the Chinese Society of Critical Care Medicine VAP guidelines (11) which are comparable to ERS VAP criteria (9). This cohort were divided into a model group $(\mathrm{n}=908)$ and a verification group $(\mathrm{n}=605)$. Multivariate logistic regression analysis was used to identify independent risk factors for development of VAP in the model group, with odds ratios for statistically significant risk factors used to generate a risk scoring system. This scoring system was then validated in the verification cohort, with a ROC curve used to determine sensitivity and specificity of the risk grading system for prediction of VAP.

This was a well-conceived study, with a large cohort recruited and rigorous statistical methodology. The incidence of VAP at 15 per 1,000 ventilator days is comparable to published rates. The independent risk factors identified as predictive for VAP were ICU LOS, duration of ventilation, presence of tracheostomy, combined antibiotic use, APACHE score, frequency of oral care and subglottic secretion management. All have been previously established as risk factors for VAP, with the latter two being the focus of much research focus in VAP prevention. The resultant VAP risk grading system is thus plausible. Its clinical utility is open to debate however. The risk factors with the highest 
score were ICU LOS of 9 days or more and duration of ventilation of 8 days or more, ascribed 5 points and 3 points respectively in the scoring system. This score would therefore have limited utility in determining risk of VAP within the first week of a patient's admission to ICU. Cook et al. have estimated that the risk of developing VAP is highest in the first 5 days, at $3 \%$ per day (12). Additionally, a frequency of oral care of $<3$ per day (score of 4 ) and lack of subglottic secretion drainage (score of 2) was also included in the risk scoring system. Chinese guidelines mandate both interventions in the prevention of VAP, and thus a ventilated patient being managed according to these guidelines would not be expected to register either score (11).

Other scores have been proposed as diagnostic tools in VAP, notably the Clinical Pulmonary Infection Score (CPIS), first proposed by Pugin et al. in 1991 (13). This incorporates clinical, radiographic and biochemical parameters to diagnose VAP, with a score greater than 6 associated with a sensitivity of $93 \%$ and a specificity of $100 \%$ for VAP in the initial study. This score is only applicable to patients already clinically suspected of having VAP however, and is dependent on the results of tracheal aspirate culture, thus delaying utility by $48 \mathrm{~h}$. Others have found that the CPIS did not differ in patients with and without VAP, as determined by subsequent bronchoalveolar lavage culture (14). Alternatively, the APACHE II score has been shown to predict mortality from VAP, with a ROC AUC $0.81(\mathrm{P}=0.001)$ (15) but has no utility in predicting risk of VAP onset.

VAP will remain an important healthcare challenge in all regions of the world, with diagnostic criteria, prevention and treatment strategies open to continuous refinement. The authors of the current paper should be commended for their contribution to an important issue, particularly in shedding light on the risk factors for VAP in their region, which are strikingly similar to those reported elsewhere. In our experience, position of the patient is also an important matter. The usual position is supine position (16). The use of nasogastric or orogastric tubes, and the presence of contents in the stomach contribute to the reflux of gastric contents, aspiration, and VAP. Semi-recumbent positioning at $30^{\circ}$ has shown to avoid these problems, as reported in a meta-analysis that included data from ten randomized clinical trials (17). The lateral Trendelenburg body position has shown both no significant benefit, and an increase in the number of adverse events (18). Rather than prediction of VAP however, a focus on guideline-mandated and evidencebased preventative strategies (such as those included in VAP bundles) for all mechanically ventilated patients is likely to be a more fruitful approach. This is true even in resourcelimited areas, given the economic burden of VAP and the proven cost-benefit of preventative strategies (19).

\section{Acknowledgments}

Funding: None.

\section{Footnote}

Conflicts of Interest: Both authors have completed the ICMJE uniform disclosure form (available at http://dx.doi. org/10.21037/atm.2020.03.173). The authors have no conflicts of interest to declare.

Ethical Statement: The authors are accountable for all aspects of the work in ensuring that questions related to the accuracy or integrity of any part of the work are appropriately investigated and resolved.

Open Access Statement: This is an Open Access article distributed in accordance with the Creative Commons Attribution-NonCommercial-NoDerivs 4.0 International License (CC BY-NC-ND 4.0), which permits the noncommercial replication and distribution of the article with the strict proviso that no changes or edits are made and the original work is properly cited (including links to both the formal publication through the relevant DOI and the license). See: https://creativecommons.org/licenses/by-nc-nd/4.0/.

\section{References}

1. Wyncoll D, Camporota L. Number needed to treat and cost-effectiveness in the prevention of ventilator-associated pneumonia. Crit Care 2012;16:430.

2. Erbay RH, Yalcin AN, Zencir M, et al. Costs and risk factors for ventilator-associated pneumonia in a Turkish university hospital's intensive care unit: a case-control study. BMC Pulm Med 2004;4:3.

3. Rosenthal VD, Bijie H, Maki DG, et al. International Nosocomial Infection Control Consortium (INICC) report, data summary of 36 countries, for 2004-2009. Am J Infect Control 2012;40:396-407.

4. Alvarez Lerma F, Sanchez Garcia M, Lorente L, et al. Guidelines for the prevention of ventilator-associated pneumonia and their implementation. The Spanish "ZeroVAP" bundle. Med Intensiva 2014;38:226-36. 
5. Zuschneid I, Schwab F, Geffers C, et al. Trends in ventilator-associated pneumonia rates within the German nosocomial infection surveillance system (KISS). Infect Control Hosp Epidemiol 2007;28:314-8.

6. Nussenblatt V, Avdic E, Berenholtz S, et al. Ventilatorassociated pneumonia: overdiagnosis and treatment are common in medical and surgical intensive care units. Infect Control Hosp Epidemiol 2014;35:278-84.

7. Stevens JP, Kachniarz B, Wright SB, et al. When policy gets it right: variability in u.s. Hospitals' diagnosis of ventilator-associated pneumonia*. Crit Care Med 2014;42:497-503.

8. Klompas M. Complications of mechanical ventilation-the CDC's new surveillance paradigm. N Engl J Med 2013;368:1472-5.

9. Torres A, Niederman MS, Chastre J, et al. International ERS/ESICM/ESCMID/ALAT guidelines for the management of hospital-acquired pneumonia and ventilator-associated pneumonia: Guidelines for the management of hospital-acquired pneumonia (HAP)/ ventilator-associated pneumonia (VAP) of the European Respiratory Society (ERS), European Society of Intensive Care Medicine (ESICM), European Society of Clinical Microbiology and Infectious Diseases (ESCMID) and Asociacion Latinoamericana del Torax (ALAT). Eur Respir J 2017. doi: 10.1183/13993003.00582-2017.

10. Liu W, Jiao Y, Xing H, et al. Active surveillance of ventilator-associated pneumonia in the intensive care unit and establishment of the risk grading system and effect evaluation. Ann Transl Med 2019;7:617.

11. Shi Y, Huang Y, Zhang TT, et al. Chinese guidelines for the diagnosis and treatment of hospital-acquired pneumonia and ventilator-associated pneumonia in adults (2018 Edition). J Thorac Dis 2019;11:2581-616.

Cite this article as: McEnery T, Martin-Loeches I. Predicting ventilator-associated pneumonia. Ann Transl Med 2020;8(11):670. doi: 10.21037/atm.2020.03.173
12. Cook DJ, Walter SD, Cook RJ, et al. Incidence of and risk factors for ventilator-associated pneumonia in critically ill patients. Ann Intern Med 1998;129:433-40.

13. Pugin J, Auckenthaler R, Mili N, et al. Diagnosis of ventilator-associated pneumonia by bacteriologic analysis of bronchoscopic and nonbronchoscopic "blind" bronchoalveolar lavage fluid. Am Rev Respir Dis 1991;143:1121-9.

14. Fartoukh M, Maitre B, Honore S, et al. Diagnosing pneumonia during mechanical ventilation: the clinical pulmonary infection score revisited. Am J Respir Crit Care Med 2003;168:173-9.

15. Gursel G, Demirtas S. Value of APACHE II, SOFA and CPIS scores in predicting prognosis in patients with ventilator-associated pneumonia. Respiration 2006;73:503-8.

16. Drakulovic MB, Torres A, Bauer TT, et al. Supine body position as a risk factor for nosocomial pneumonia in mechanically ventilated patients: a randomised trial. Lancet 1999;354:1851-8.

17. Wang L, Li X, Yang Z, et al. Semi-recumbent position versus supine position for the prevention of ventilator-associated pneumonia in adults requiring mechanical ventilation. Cochrane Database Syst Rev 2016;(1):CD009946.

18. Li Bassi G, Panigada M, Ranzani OT, et al. Randomized, multicenter trial of lateral Trendelenburg versus semirecumbent body position for the prevention of ventilator-associated pneumonia. Intensive Care Med 2017;43:1572-84.

19. Branch-Elliman W, Wright SB, Howell MD. Determining the Ideal Strategy for Ventilator-associated Pneumonia Prevention. Cost-Benefit Analysis. Am J Respir Crit Care Med 2015;192:57-63. 